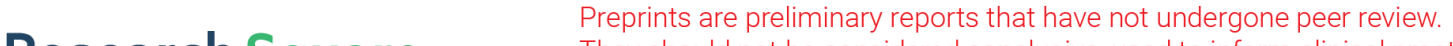 They should not be considered conclusive, used to inform clinical practice, or referenced by the media as validated information. \\ Pacific Decadal Oscillation Causes Fewer Near- Equatorial Cyclones in North Indian Ocean
}

\section{Shinto Roose}

Cochin University of Science \& Technology

Ajayamohan Ravindran ( $\sim$ Ajaya.Mohan@nyu.edu )

New York University Abu Dhabi https://orcid.org/0000-0002-4513-4905

\section{Pallav Ray}

Florida Institute of Technology https://orcid.org/0000-0001-8924-1852

\section{Shang-Ping Xie}

Scripps Institution of Oceanography https://orcid.org/0000-0002-3676-1325

Cherumadanakadan Thelliyil Sabeerali

New York University Abu Dhabi

\section{Mohapatra}

India Meteorological Department

\section{Sourav Taraphdar}

New York University Abu Dhabi

\section{Kesavapillai Mohanakumar}

Cochin University of Science \& Technology

\section{Rajeevan}

Indian Institute of Tropical Meteorology

\section{Article}

Keywords: tropical cyclones, climate change, Pacific Decadal Oscillation (PDO).

Posted Date: June 23rd, 2021

DOI: https://doi.org/10.21203/rs.3.rs-566899/v1

License: (c) (i) This work is licensed under a Creative Commons Attribution 4.0 International License.

Read Full License 


\title{
Pacific Decadal Oscillation Causes Fewer Near-Equatorial Cyclones in the North Indian Ocean
}

\author{
Shinto Roose ${ }^{1,2}$, R. S. Ajayamohan ${ }^{1, *}$, Pallav Ray ${ }^{3}$, Shang-Ping $\mathrm{Xie}^{4}$, C. T. Sabeerali ${ }^{1}$, M. \\ Mohapatra $^{5}$, S. Taraphdar ${ }^{1}$, K. Mohanakumar ${ }^{6}$, and M. Rajeevan ${ }^{7}$
}

\author{
${ }^{1}$ The Center for Prototype Climate Modeling, New York University Abu Dhabi, Abu Dhabi, UAE \\ ${ }^{2}$ Department of Atmospheric Sciences, Cochin University of Science and Technology, India \\ ${ }^{3}$ Meteorology, Florida Institute of Technology, Melbourne, FL, USA \\ ${ }^{4}$ Scripps Institute of Oceanography, University of California San Diego, CA, USA \\ ${ }^{5}$ India Meteorological Department, New Delhi, India \\ ${ }^{6}$ Advanced Centre for Atmospheric Radar Research, Cochin University of Science and Technology, India \\ ${ }^{7}$ Ministry of Earth Sciences, New Delhi, India \\ *Ajaya.Mohan@nyu.edu
}

\section{ABSTRACT}

Tropical cyclones do not form easily near the equator but can intensify rapidly, leaving little time for preparation. We investigated the number of near-equatorial (originating between $5^{\circ} \mathrm{N}$ and $11^{\circ} \mathrm{N}$ ) tropical cyclones over the north Indian Ocean during post-monsoon seasons (October to December) over the past 60 years. A marked $43 \%$ decline in the number of such cyclones was detected in recent decades (1981-2010) compared to earlier (1951-1980). This decline in tropical cyclone frequency is primarily due to the weakened low-level vorticity modulated by the Pacific Decadal Oscillation (PDO). In the presence of basin-wide warming at low latitudes, and a favorable phase of the PDO, both the intensity and frequency of such cyclones is expected to increase. Such dramatic and unique changes in tropical cyclonic activity due to the interplay between natural variability and climate change call for appropriate planning and mitigation strategies.

\section{Introduction}

Tropical cyclones (TCs) are far fewer in the vicinity of the equator because of small Coriolis force that cannot provide the initial spin-up of the cyclonic vortex ${ }^{1}$. On average, there are fewer than two cyclones per year within $5^{\circ}$ latitude of the equator, with the majority originating in the Western Pacific Ocean ${ }^{2}$. A little away from the equator, however, TCs can form more easily in the presence of larger Coriolis force and other favorable environmental conditions. These low-latitude cyclones (LLCs, originating between $5^{\circ}-11^{\circ}$ latitude) are much smaller in size than those in higher latitudes but intensify more rapidly ${ }^{3-5}$ as the boundary layer inflow closer to the cyclonic center is higher in the presence of smaller Coriolis force (smaller inertial instability). The strong boundary layer inflow enhances diabatic heating rates ${ }^{5}$ that induce stronger secondary circulation leading to enhanced boundary layer moisture convergence ${ }^{6-8}$ at low latitudes. This positive feedback mechanism spins up the system more rapidly at low latitudes.

The north Indian Ocean (NIO) in the post-monsoon season (October-November-December or OND) is a hotbed for LLCs that constitute about $60 \%$ of all TCs formed in the NIO (since 1951$)^{9}$ but has received relatively less attention. The rapid intensification of LLCs leads to devastating damages due to the insufficient warning and preparation time. For example, LLC Ockhi traveled over $2000 \mathrm{Km}$ and devastated parts of Sri Lanka and India with extensive damage to properties and loss of lives of 884 people in November $2017^{10}$. Such devastating impact from the NIO LLCs motivates us to study the variability of the LLC with the available data. It is interesting to note that the Indian Ocean basin has warmed consistently and more than any other ocean basin ${ }^{11-13}$. Since the genesis of tropical cyclones are closely linked with the underlying Sea Surface Temperature $(\mathrm{SST})^{1,14}$, a study on the association of trends in the SST and LLC assumes significance.

\section{Results}

\section{Epochal changes in the low-latitude cyclones in the Bay of Bengal}

Based on the categorization of TCs, 72 LLCs formed over the $\mathrm{BoB}\left(83^{\circ} \mathrm{E}\right.$ and $\left.95^{\circ} \mathrm{E}\right)$ in the last sixty years $(1951-2010)$ which constitute about $75 \%$ of the total NIO LLCs ${ }^{9,15}$. We define two 30-year epochs viz. epoch-1 (1951-1980, Fig. 1a) and epoch-2 (1981-2010, Fig. 1b) to study the post-monsoonal LLC activity. The decline in the genesis of LLC over the BoB is prominent as only 26 TCs ( 121 TC days) were formed in the epoch- 2 compared to 46 ( 290 TC days) in the epoch-1, indicating a $\approx 40 \%$ 
decline in the LLC frequency ( $\approx 60 \%$ decline in the TC days; Fig. 1). This decline in LLC frequency is evident over all three months of the post-monsoonal season over the BoB (Fig. S1). The epochal trend in LLC frequency arises primarily from the genesis of large number of LLCs during sixties (1961-1970) and seventies (1971-1980) (Fig. 1c). While a record number of 19 LLCs formed during sixties and seventies, other decades reports 8-10 LLCs (Fig. 1c). Over the entire NIO, the decline of TCs is dominant in the latitude belt $5^{\circ}-11^{\circ} \mathrm{N}$ (Fig. 1d). The number of TCs north of $11^{\circ} \mathrm{N}$ increased from 23 to 37 during the same time (Fig. 1d). As a result, in the entire NIO, the change in frequency of TCs is much smaller than the change in LLC.

The frequency of LLC in the pre-monsoon season (April-May) is much smaller than that in the post-monsoon season, but a decline in the frequency of LLC is also evident in the pre-monsoon season (Fig. S2, Tab. S2). Other available TC datasets over the NIO basin also shows a similar decline (Tab. S3). Here, we aim to address the causes behind the remarkable decline in LLC frequency in BoB in the post-monsoon season, specifically its dependence on the large-scale environmental factors during 1951-2010. The erudition obtained from such an investigation may aid in enhancing the understanding and prediction of LLC over the NIO.

(a) Epoch-1

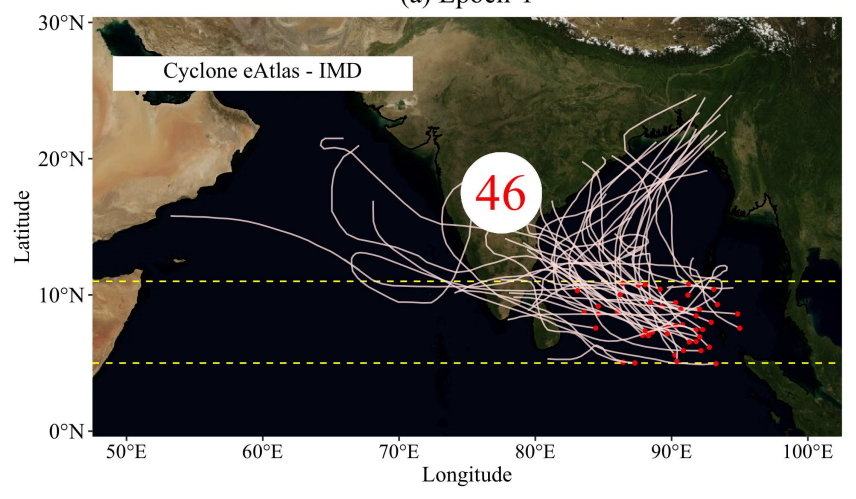

(c) Decadal Changes in LLC

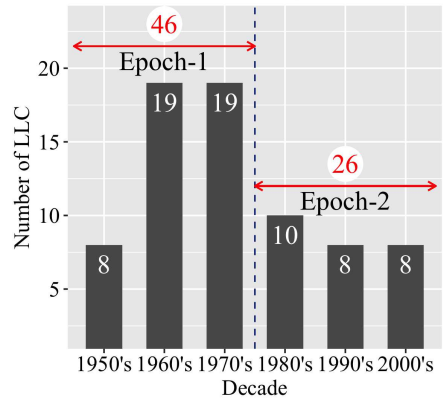

(d) Epochal change in NIO cyclones

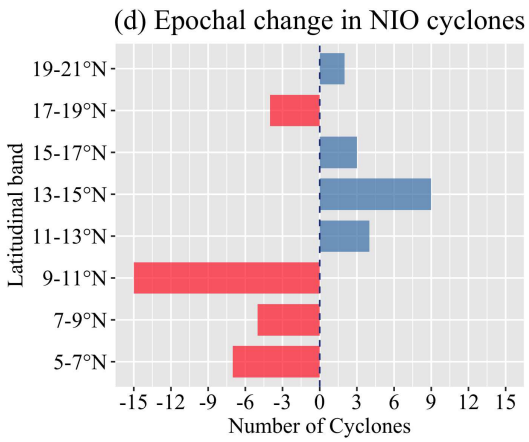

(b) Epoch-2

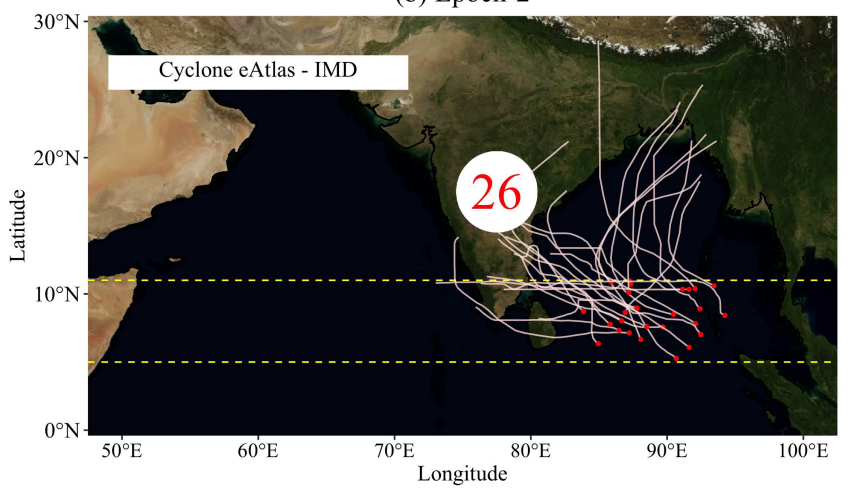

(e) Epochal change in LLC against longitudes

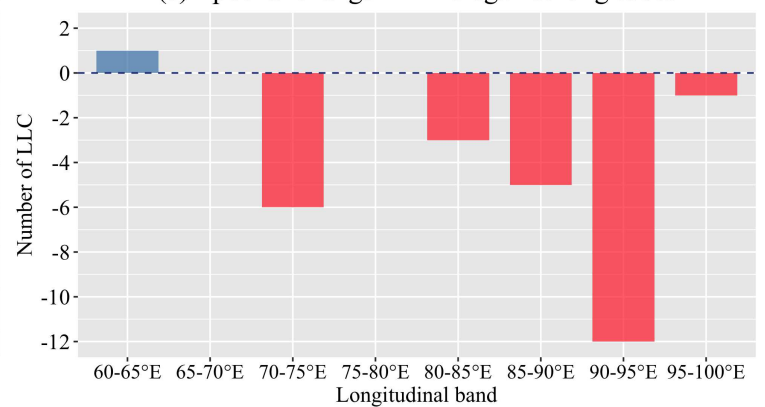

Figure 1. The number of LLCs and their tracks over the $\mathrm{BoB}\left(83^{\circ}-95^{\circ} \mathrm{E}, 5^{\circ}-11^{\circ} \mathrm{N}\right)$ in the post-monsoon seasons $(\mathrm{OND})$ during (a) epoch-1 (1951-1980) and (b) epoch-2 (1981-2010). The dashed lines denote the low-latitudinal belt $\left(5^{\circ}-11^{\circ} \mathrm{N}\right)$. The red labels represent the total number of LLCs. (c) Decadal variation in the number of LLC formed over BoB. (d) Latitudinal distribution of the epochal difference in the number of cyclones in the north Indian Ocean. (e) Logitudinal distribution of epochal difference in the number of LLCs $\left(5^{\circ}-11^{\circ} \mathrm{N}\right)$. Cyclonic storms $(>34$ knots) and severe cyclonic storms ( $>48$ knots) are considered in this study ${ }^{9}$.

\section{Epochal changes in the factors that control low-latitude cyclones in the Bay of Bengal}

The major factors responsible for the genesis of TCs are SST, oceanic heat content, mid-tropospheric humidity, and vertical shear of the horizontal winds and absolute vorticity ${ }^{1,16}$. Consistent with the warming trend in the Indian Ocean ${ }^{12,13}$, a warming of $0.5^{\circ} \mathrm{C}$ is found over the low latitudinal belt of the BoB in the past sixty years (1951-2010, Fig. 2a). The warming SST, which is much above the SST threshold $\left(26^{\circ} \mathrm{C}\right)$ for cyclogenesis ${ }^{17}$, is expected to support an increase in frequency and intensity of TCs ${ }^{18-22}$, yet the number of BoB LLCs has decreased (Fig. 1). The tropical cyclone heat potential (TCHP), another vital parameter concerning the genesis and intensification of $\mathrm{TCs}^{23}$, also shows an increasing trend over BoB during 1981-2010 (Fig. 2b) similar to the global oceans ${ }^{24}$. Therefore, a decline in the BoB LLC frequency cannot be attributed to an increase in TCHP. All the above oceanic (SST, TCHP) parameters are working synergistically to create a conducive environment for TC 
genesis.

The mid-tropospheric relative humidity doesn't show any epochal variation (Fig. 2c), and hence cannot aid a reduction in LLC frequency. Another important circulation feature that influences cyclogenesis and its intensity is the vertical shear of the horizontal wind, which allows the ventilation of mid-level moisture out of the inner core of the cyclone ${ }^{25}$. As a result, the vertical shear of the intensifying TCs is lower than that of the non-intensifying $\mathrm{TCs}^{25}$. The vertical shear increased only slightly by $0.3 \mathrm{~ms}^{-1}$ during 1981-2010 (Fig. 2d), which is unlikely to support such an epochal decline in the BoB LLC frequency ${ }^{22,26}$. The most significant factor that seems to support the decline in LLC frequency in epoch-2 is the low-level absolute vorticity, which has reduced substantially (Fig. 2e,f). The reduced absolute vorticity during epoch-2 seems to be responsible for a fewer number of LLCs, especially over $90^{\circ} \mathrm{E}-95^{\circ} \mathrm{E}$ region (Fig 1e), where the changes in absolute vorticity is the largest (Fig. 2f). The dynamics behind the epochal variation of low-level vorticity in the low-latitudes and its association with the low-level winds and LLC trend are examined further.
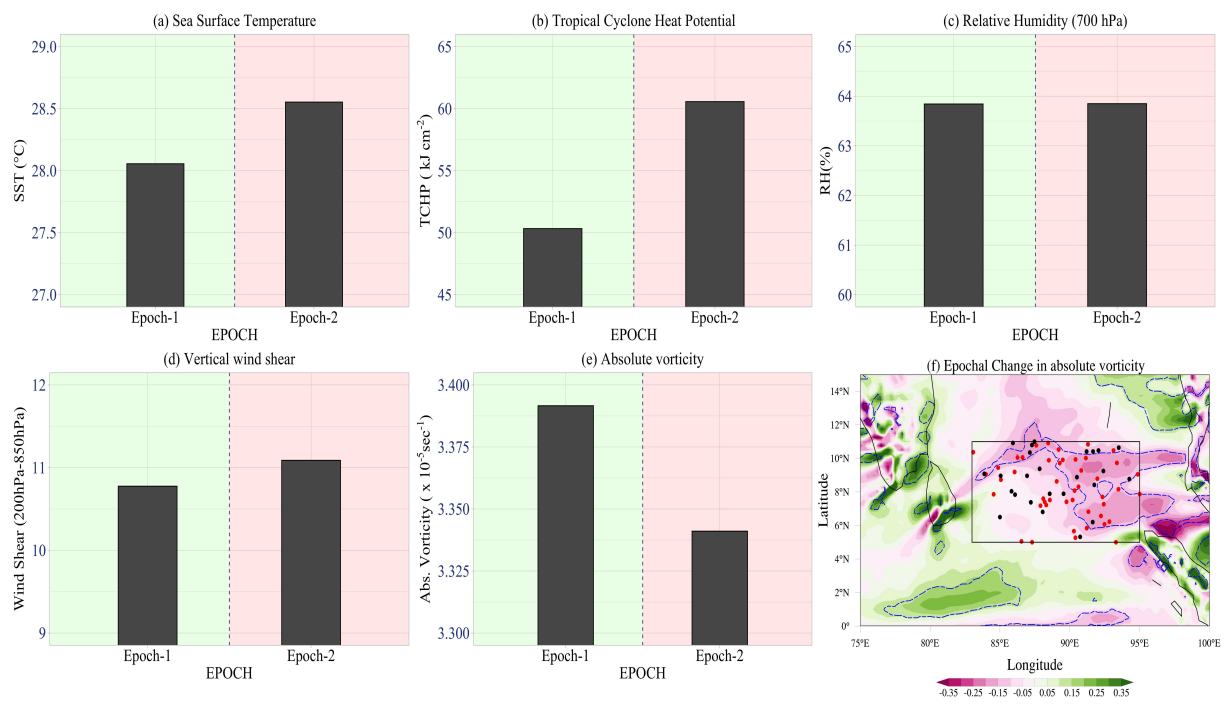

Figure 2. Epochal mean of (a) sea surface temperature $\left({ }^{\circ} \mathrm{C}\right)(\mathrm{b})$ tropical cyclone heat potential $\left(\mathrm{kJcm}^{-2}\right)$, (c) mid-tropospheric $(700 \mathrm{hPa})$ relative humidity (\%), (d) vertical wind shear between 850 and $200 \mathrm{hPa}\left(\mathrm{ms}^{-1}\right)$, and (e) Low-level (850hPa) absolute vorticity $\left(\mathrm{x} 10^{-5} \mathrm{~s}^{-1}\right)$ averaged over $5^{\circ}-11^{\circ} \mathrm{N}, 83^{\circ}-95^{\circ} \mathrm{E}$ during post-monsoon season. The green (red) background indicates epoch-1 (epoch-2) in panels (a)-(e). (f) Epochal change (epoch-2 minus epoch-1) in $925 \mathrm{hPa}$ absolute vorticity ( $10^{-5} \mathrm{~s}^{-1}$ ). Dashed contours represent statistical significance at $90 \%$ confidence level. Genesis locations of LLCs are marked as dots in red (epoch-1) and black (epoch-2).

\section{Mechanism of epochal decline in low-level vorticity}

The westerly winds dominate over the equatorial Indian Ocean during the pre- and post-monsoon seasons with a shift to weak westerlies during the monsoon season ${ }^{27}$. These low-level equatorial westerlies play an important role in the cyclogenesis over the Indian Ocean. The relative vorticity over the low latitudinal belt $\left(5^{\circ} \mathrm{N}-11^{\circ} \mathrm{N}\right)$ is stronger during the peaks of equatorial westerlies in both pre- and post-monsoon seasons. This leads to the formation of cyclonic circulation on either side of the equator, one between $5^{\circ} \mathrm{N}-11^{\circ} \mathrm{N}$ and another between $5^{\circ} \mathrm{S}-11^{\circ} \mathrm{S}$ (Fig. 3a). During the monsoon period, however, intense cyclones do not form over the NIO due to weak relative vorticity in the presence of strong easterly wind shear ${ }^{28}$. The difference in wind patterns between the two epochs clearly shows the strengthening of equatorial westerlies south of the equator (Fig. 3b, vector). This strengthening of westerlies results in the formation of a cyclonic gyre north of the peak westerly winds in the equatorial region $\left(0^{\circ}-5^{\circ} \mathrm{N}\right.$, Fig. $\left.3 \mathrm{~b}\right)$. This shift of the cyclonic gyres towards the equator can no longer support cyclogenesis as the Coriolis force is negligible close to the equator. This insufficient background rotation explains the reduction in cyclogenesis in recent epoch over this region.

The latitudinal shift in the equatorial westerlies and its association with the epochal changes in LLC is further investigated by estimating the changes in the latitudinal position of zero absolute vorticity ${ }^{29}(\eta=0$; Fig. $4 \mathrm{a})$. The southward shift in the zero absolute vorticity by $\approx 0.75^{\circ} \mathrm{N}$ in thirty years (1960-1990) complies with the decline in the number of LLC (Fig. 4b). This shift of the cyclonic gyres towards the equator leads to 2 TCs in epoch- 2 compared to no TCs in epoch- 1 within $0^{\circ}-3^{\circ} \mathrm{N}^{30,31}$, but causes a much larger decrease in TC frequency in $5^{\circ} \mathrm{N}-11^{\circ} \mathrm{N}$ due to reduced vorticity. While 12 out of $46 \mathrm{TCs}$ intensified into severe cyclonic storms (SCS; above 48 Knots) before crossing $11^{\circ} \mathrm{N}$ in epoch- 1,8 out of 26 TCs became SCS in epoch-2 
(Fig. 4b). This represents a marginal increase of TCs to attain higher intensity in epoch-2 compared to epoch-1.

(a)

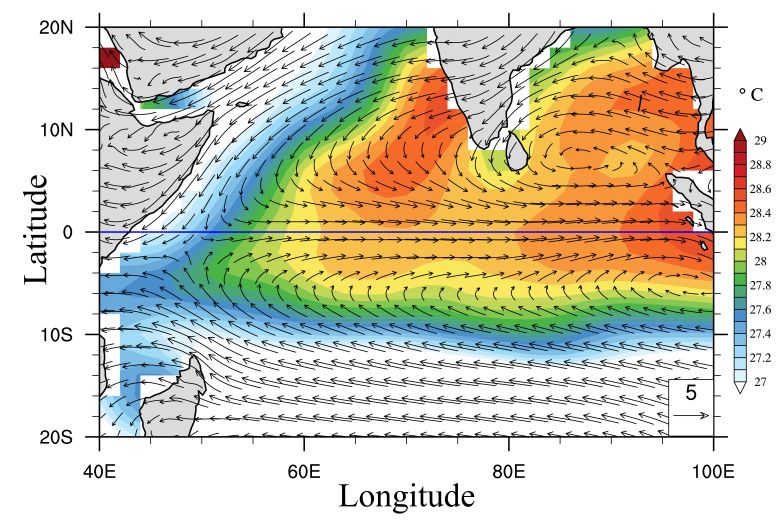

(b)

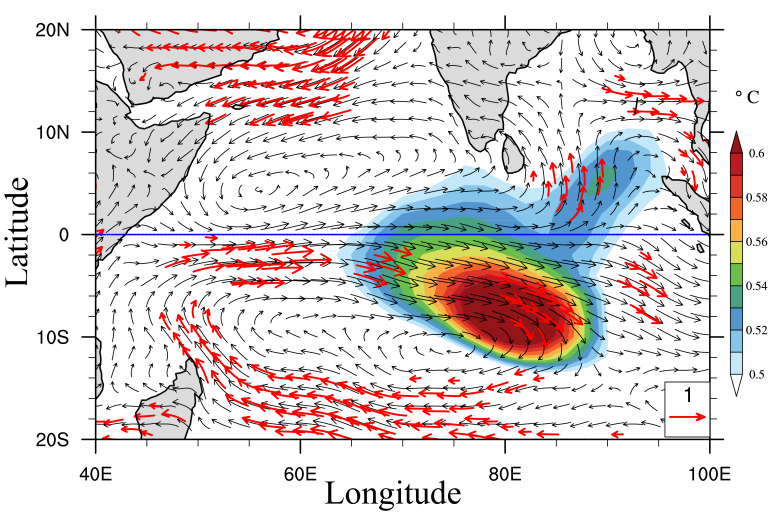

Figure 3. (a) Post-monsoon seasonal mean of SST $\left({ }^{\circ} \mathrm{C}\right.$, shaded) and $850 \mathrm{hPa}$ winds (vector) in the tropical Indian Ocean and their (b) epochal difference (epoch2-epoch1; shaded contours and red arrows are statistically significant at 95\% confidence level).

\section{Epochal variation in low-level vorticity and its connection with the Pacific Decadal Oscillation}

The apparent epochal variation in lower-tropospheric absolute vorticity (Fig. 2e) and its latitudinal shift (Fig. 4a) motivate us to explore whether they are related to the Pacific Decadal Oscillation (PDO), which is the dominant climate variability in the decadal timescales ${ }^{32-34}$. It is found that the positive phase of the PDO coincides with the epochal decline of LLC during the post-monsoon season (Fig. 4c). The association of PDO phases and LLC leads to the conjecture that the latitudinal shift in westerlies is strongly associated with the PDO phases. To confirm this relationship, a regression analysis of the decadal signal of SST and low-level winds with the PDO index is carried out. The resultant pattern (Fig. 4d) is similar to the pattern seen in Fig. $3 \mathrm{~b}$ with peak SST anomalies around $80^{\circ} \mathrm{E}$ and $7^{\circ} \mathrm{S}$. This provides further evidence that the epochal difference of the SST and the low-level winds are associated with the PDO phases through the latitudinal shift in equatorial westerlies (Fig. 3b). The tropical wide view of the difference in velocity potential and the associated divergent winds shows an anomalous low-level convergence over the central tropical Pacific and Indian Ocean in response to the cold to warm phase transition of PDO from epoch-1 to epoch-2 (Fig. S3). The core of the anomalous convergence in the Indian Ocean is south of the equator (Fig. S3a). The anomalous divergence over the central Pacific and Indian oceans are much more intense in the upper level (Fig. S3b). The Coriolis force acting on the southward ageostrophic flow induces the anomalous westerlies (easterlies) south (north) of the equator. This complies with the change in the strength of the Walker circulation associated with the PDO phases. The epochal changes in the SST and the low-level winds (Fig. 4d) are associated with the PDO phases, leading to the southward shift in equatorial westerlies (Fig. 3b).

Several studies ${ }^{35-37}$ have questioned the reliability of the TC data in the pre-satellite era due to the change in technology and analysis protocols. Most of these studies hint at underestimation of the intensity of TCs in the pre-satellite era. After a detailed analysis of the NIO TC data ${ }^{15}$ from 1871-2010, it was found that the best-track data from the 1960 s is reliable (see SI Appendix). The declining trend in the frequency in the recent epoch is also apparent and more pronounced if the period of the study is limited to 1961-2010. The TC intensity data before 1980 depends on ship track density, polar orbiting satellite intervals and the density of the coastal observing stations. Given the uncertainty in the quality of the pre-satellite era TC intensity data, the results on the marginal increase in the strength of LLCs in the recent epoch must be interpreted with caution. Our analysis for this study is limited to the post-1950 period because of the larger uncertainties in TC data prior to 1950. Therefore, there is only one cycle of PDO and any competing influence from the increased anthropogenic greenhouse gases resulting in increased surface temperature and changes in circulation, cannot be eliminated. Despite these complexities, the evolution of PDO indices and the latitudinal position of zero absolute vorticity $(\eta=0)$ for the period 1900-2010 show a statistically significant correlation indicating the robustness of this relationship (Fig. S4). The mismatch between these two time series is more evident before 1920 , data is less reliable.

\section{Conclusions}

We conclude that the recent epoch (epoch-2, 1981-2010) has seen a remarkable decline in the post-monsoon LLC frequency over the north Indian Ocean in comparison with the earlier epoch (epoch-1, 1951-1980). This decline in LLC frequency (Fig. 1) 
cannot be attributed to an increasing SST and oceanic heat content, nearly unchanged mid-tropospheric humidity, or a slightly decreasing vertical wind shear (Fig. 2). The decline in LLC frequency in the recent epoch seems to be primarily caused by the reduced low-level vorticity (Fig 2e,f) due to southward displacement in equatorial westerly winds. The strong equatorial westerlies lead to the formation of cyclonic circulation on either side of the equator within the belts of $5^{\circ} \mathrm{N}-11^{\circ} \mathrm{N}$ and $5^{\circ}-11^{\circ} \mathrm{S}$ (Fig. 3b). This southward displacement of equatorial westerlies (Fig. 3b) in the recent epoch is strongly associated with the PDO (Fig. 4c-d, Fig. S3-S4). Although the LLC frequency has decreased in epoch-2, once an LLC is formed, favorable thermodynamic conditions in the low-latitudes and north of $11^{\circ} \mathrm{N}$ lead to the strengthening of the cyclonic storms in recent decades ${ }^{18,19,22}$. However, the strengthening of LLCs in recent decades must be interpreted with caution due to the unreliability in the TC intensity data in the pre-satellite era.

The results present an interesting situation where remote influence by natural climate variability (PDO) causes fewer cyclones, but favorable local thermodynamic conditions due to global warming make them slightly stronger ${ }^{19,38}$. When this tug-of-war between the natural and anthropogenic forcing changes and they begin to work synergistically, the risk of severe cyclones in the post-monsoon north Indian Ocean may be amplified. These results may guide planning and mitigating LLC-induced disaster in the Indian subcontinent. The models with poor PDO simulation, therefore, should be treated with caution when they are used for future projections of LLC over the north Indian Ocean.

(a)

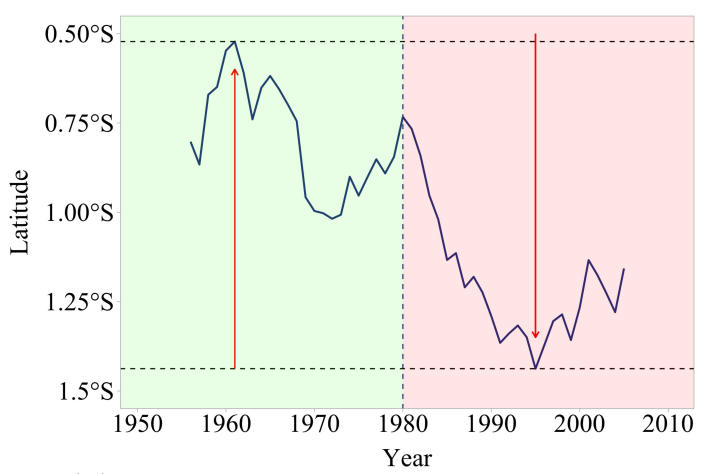

(c)

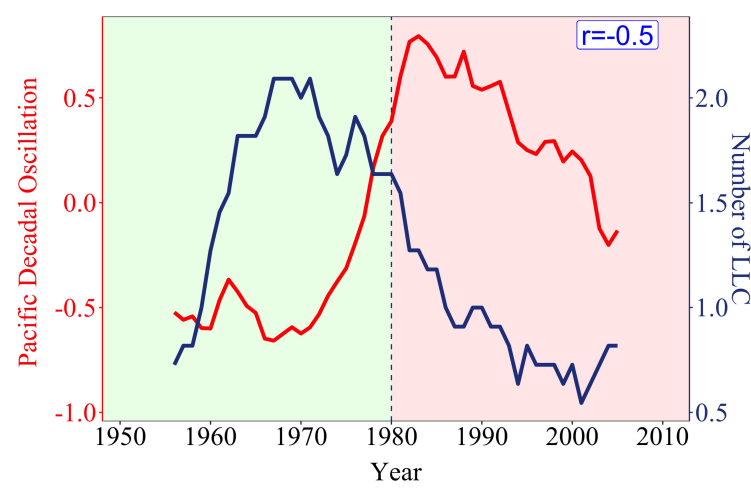

(b)

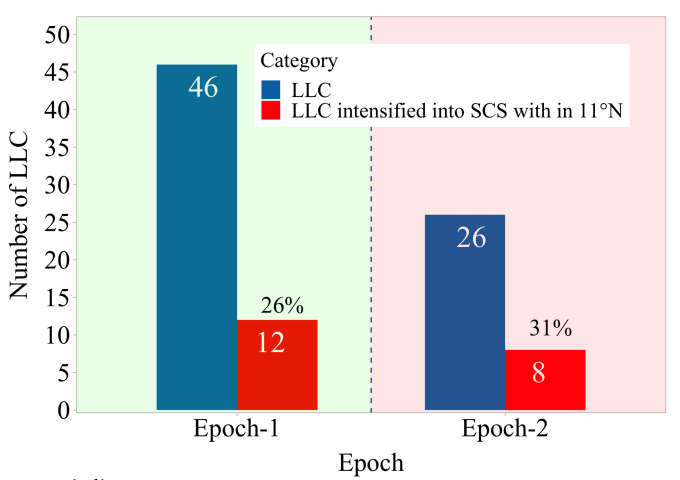

(d)

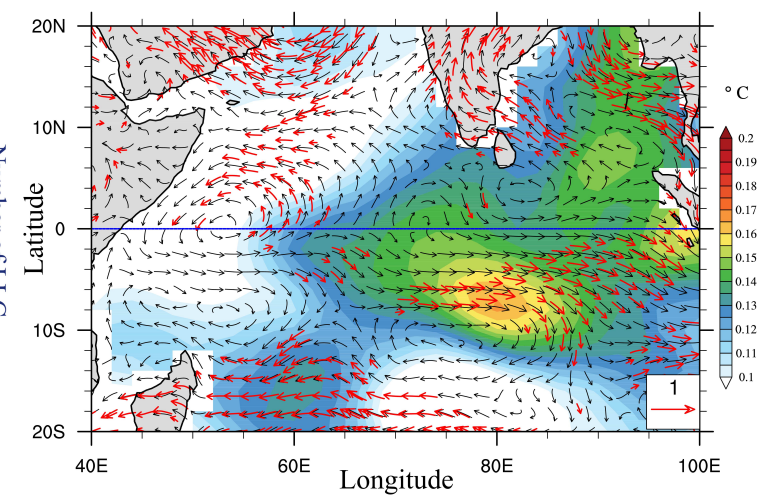

Figure 4. (a) Latitudinal position of zero absolute vorticity $(850 \mathrm{hPa})$ at $80^{\circ} \mathrm{E}$. (b) epochal change in different categories of LLC. (c) Smoothed PDO index (red) and the number of LLCs (blue) in the Bay of Bengal. The vertical dashed lines separate the two epochs. The correlation between two time series is denoted is also shown. (d) Regressions of the smoothed PDO index onto SST (shaded) and $850 \mathrm{hPa}$ winds (vector) for the period 1951-2010. All calculations were performed for the post-monsoon (OND) season except for PDO. A 11-year running mean is used to smooth the time series in (a), (c) and (d) to isolate the decadal signal. 


\section{Methods}

We use the ERA5 reanalysis data ${ }^{39,40}$ from 1951-2010 to understand the epochal variation of atmospheric parameters. Monthly mean ocean temperature data from the UK Met Office Hadley Centre ${ }^{41}$ is used to estimate TCHP. The Extended Reconstructed Sea Surface Temperature dataset, version 5 (ERSSTv $5^{42}$ ) from the National Oceanic and Atmospheric Administration (NOAA) is used. The tracks and number of cyclones formed between 1951 and 2010 were obtained from the archives of the India Meteorological Department ${ }^{43}$. The basemap in Fig. 1 is based on the satellite image from the Blue Marble Next Generation, NASA's Earth Observatory.

\section{References}

1. Gray, W. M. Global view of the origin of tropical disturbances and storms. Mon. Weather. Rev. 96, 669-700, DOI: 10.1175/1520-0493(1968)096<0669:GVOTOO>2.0.CO;2 (1968).

2. Steenkamp, S. C., Kilroy, G. \& Smith, R. K. Tropical cyclogenesis at and near the equator. Quart. J. Roy. Meteorol. Soc. 145, 1846-1864, DOI: 10.10002/sj.3529 (2019).

3. DeMaria, M. \& Pickle, J. D. A simplified system of equations for simulation of tropical cyclones. J. Atmos. Sci. 45, 1542-1554, DOI: 10.1175/1520-0469(1988)045<1542:ASSOEF>2.0.CO;2 (1988).

4. DeMaria, M., Knaff, J. A. \& Connell, B. H. A tropical cyclone genesis parameter for the tropical Atlantic. Weather. Forecast. 16, 219-233, DOI: 10.1175/1520-0434(2001)016<0219:ATCGPF>2.0.CO;2 (2001).

5. Smith, R. K., Kilroy, G. \& Montgomery, M. T. Why do model tropical cyclones intensify more rapidly at low latitudes? J. Atmos. Sci. 72, 1783-1804, DOI: 10.1175/JAS-D-14-0044.1 (2015).

6. Hack, J. J. \& Schubert, W. H. Nonlinear response of atmospheric vortices to heating by organized cumulus convection. $J$. Atmos. Sci. 43, 1559-1573, DOI: 10.1175/1520-0469(1986)043<1559:NROAVT>2.0.CO;2 (1986).

7. Schubert, W. H. \& Hack, J. J. Inertial stability and tropical cyclone development. J. Atmos. Sci. 39, 1687-1697, DOI: 10.1175/1520-0469(1982)039<1687:ISATCD>2.0.CO;2 (1982).

8. Vigh, J. L. \& Schubert, W. H. Rapid development of the tropical cyclone warm core. J. Atmos. Sci. 66, 3335-3350, DOI: 10.1175/2009JAS3092.1 (2009).

9. Cyclone-eAtlas. Tracks of cyclones and depressions over north Indian Ocean. Version 2.0, Cyclone Warning \& Research Centre, India Meteorological Department, Chennai (2011). Available at http://www.rmcchennaieatlas.tn.nic.in.

10. Guha-Sapir. EM-DAT: The OFDA/CRED International Disaster Database (2017). http://www.emdat.be.

11. Alory, G., Wijffels, S. \& Meyers, G. Observed temperature trends in the Indian Ocean over 1960-1999 and associated mechanisms. J. Geophys. Res. 34, 2-7, DOI: 10.1029/2006GL028044 (2007).

12. Rao, S. A. et al. Why is Indian Ocean warming consistently? Clim. Chang. 110, 709-719, DOI: 10.1007/ s10584-011-0121-x (2012).

13. Roxy, M. K., Ritika, K., Terray, P. \& Masson, S. The Curious Case of Indian Ocean Warming. J. Clim. 27, 8501-8509, DOI: 10.1175/JCLI-D-14-00471.1 (2014).

14. Emanuel, K. Contribution of tropical cyclones to meridional heat transport by the oceans. J. Geophys. Res. 106, 14771-14781, DOI: 10.1029/2000JD900641 (2001).

15. Mohapatra, M., Bandyopadhyay, B. \& Tyagi, A. Best track parameters of tropical cyclones over the north Indian Ocean: A review. Nat. Hazards 63, 1285-1317, DOI: 10.1007/s11069-011-9935-0 (2012).

16. Emanuel, K. A. The dependence of hurricane intensity on climate. Nature 326, 483-485, DOI: 10.1038/326483a0 (1987).

17. Palmen, E. On the formation and structure of tropical hurricanes. Geophysica 3, 26-38, DOI: 10.3103/S1068373908060034 (1948).

18. Trenberth, K. Uncertainty in hurricanes and global warming. Science 308, 1753-1754, DOI: 10.1126/science.1112551 (2005).

19. Webster, P. J., Holland, G. J., Curry, J. A. \& Chang, H. R. Changes in tropical cyclone number, duration, and intensity in a warming environment. Science 309, 1844-1846, DOI: 10.1126/science.1116448 (2005).

20. Balaguru, K., Taraphdar, S., Leung, L. R. \& Foltz, G. R. Increase in the intensity of post-monsoon Bay of Bengal tropical cyclones. Geophys. Res. Lett. 41, 3594-3601, DOI: 10.1002/2014GL060197 (2014). 
21. Lin, Y., Zhao, M. \& Zhang, M. Tropical cyclone rainfall area controlled by relative sea surface temperature. Nat. Commun. 6, 1-7, DOI: $10.1038 /$ ncomms7591 (2015).

22. Murakami, H., Vecchi, G. A. \& Underwood, S. Increasing frequency of extremely severe cyclonic storms over the Arabian Sea. Nat. Clim. Chang. 7, 885-889, DOI: 10.1038/s41558-017-0008-6 (2017).

23. Leipper, D. F. \& Volgenau, D. Hurricane heat potential of the Gulf of Mexico. J. Phys. Ocean. 2, 218-224, DOI: 10.1175/1520-0485(1972)002<0218:HHPOTG>2.0.CO;2 (1972).

24. Liu, R., Chen, C. \& Wang, G. Change of tropical cyclone heat potential in response to global warming. J. Atmos. Sci. 33, 504-510, DOI: 10.1007/s00376-015-5112-9 (2016).

25. Merrill, R. T. Environmental influences on hurricane intensification. J. Atmos. Sci. 45, 1678-1687, DOI: 10.1175/ 1520-0469(1988)045<1678:EIOHI>2.0.CO;2 (1988).

26. Evan, A. T., Kossin, J. P. \& Ramanathan, V. Arabian sea tropical cyclones intensified by emissions of black carbon and other aerosols. Nature 479, 94-97, DOI: 10.1038/nature10552 (2011).

27. Ogata, T. \& Xie, S.-P. Semiannual cycle in zonal wind over the equatorial Indian Ocean. J. Clim. 24, 6471-6485, DOI: 10.1175/2011JCLI4243.1 (2011).

28. Krishnamurthy, V. \& Ajayamohan, R. S. Composite structure of monsoon low pressure systems and its relation to Indian rainfall. J. Clim. 23, 4825-4305, DOI: 10.1175/2010JCLI2953.1 (2010).

29. Sandeep, S. \& Ajayamohan, R. S. Poleward shift in Indian summer monsoon low level jetstream under global warming. Clim. Dynam. 45, 337-351, DOI: 10.1007/s00382-014-2261-y (2015).

30. Knapp, K. R., Kruk, M. C., Levinson, D. H., Diamond, H. J. \& Neumann, C. J. The international best track archive for climate stewardship (IBTrACS) unifying tropical cyclone data. Bull. Amer. Meteorol. Soc. 91, 363-376, DOI: 10.1175/2009BAMS2755.1 (2010).

31. Chu, J.-H., Sampson, C. R., Levine, A. S. \& Fukada, E. The joint typhoon warning center tropical cyclone best-tracks, 1945-2000. Tech. Rep., Joint Typhoon Warning Center, Naval Research Laboratory,Ref. NRL/MR/7540-02 (2002). Available at https://www.metoc.navy.mil/jtwc/products/best-tracks/tc-bt-report.html.

32. Mantua, N. J., Hare, S. R., Zhang, Y., Wallace, J. M. \& Francis, R. C. Pacific interdecadal climate oscillation with impacts on salmon production. Bull. Am. Meteorol. Soc. 78, 1069-1079, DOI: 10.1175/1520-0477(1997)078<1069: APICOW>2.0.CO;2 (1997).

33. Zhang, Y., Xie, S.-P., Kosaka, Y. \& Yang, J.-C. Pacific decadal oscillation: Tropical Pacific forcing versus internal variability. J. Clim. 31, 8265-8279, DOI: 10.1175/JCLI-D-18-0164.1 (2018).

34. Girishkumar, M. S., Thanga Prakash, V. P. \& Ravichandran, M. Influence of Pacific Decadal Oscillation on the relationship between ENSO and tropical cyclone activity in the Bay of Bengal during October-December. Clim. Dynam. 44, 3469-3479, DOI: $10.1007 / \mathrm{s} 00382-014-2282-6(2015)$.

35. Landsea, C. W., Harper, B. A., Hoarau, K. \& Knaff, J. A. Can we detect trends in extreme tropical cyclones? Science 313, 452-454, DOI: 10.1126/science.1128448 (2006).

36. Kossin, J. P., Olander, T. L. \& Knapp, K. R. Trend analysis with a new global record of tropical cyclone intensity. J. Clim. 26, 9960-9976, DOI: 10.1175/JCLI-D-13-00262.1 (2013).

37. Vecchi, G. A. \& Knutson, T. R. Estimating annual numbers of Atlantic hurricanes missing from the HURDAT database (1878-1965) using ship track density. J. Clim. 24, 1736-1746, DOI: 10.1175/2010JCLI3810.1 (2011).

38. Goldenberg, S. B., Landsea, C. W., Mestas-Nuñez, A. M. \& Gray, W. M. The recent increase in Atlantic hurricane activity: Causes and implications. Science 293, 474-479, DOI: 10.1126/science.1060040 (2001).

39. Hersbach, H. et al. The era5 global reanalysis. Q. J. Royal Meteorol. Soc. 146, 1999-2049, DOI: https://doi.org/10.1002/ qj.3803 (2020).

40. European Centre for Medium-Range Weather Forecasts. Era5 back extension 1950-1978 (preliminary version) (2020). Available at https://doi.org/10.5065/YBW7-YG52, Accessed 26 Nov 2020.

41. Good, S. A., Martin, M. J. \& Rayner, N. A. EN4: Quality controlled ocean temperature and salinity profiles and monthly objective analyses with uncertainty estimates. J. Geophys. Res. 118, 6704-6716, DOI: 10.1002/2013JC009067 (2013).

42. Huang, B. et al. Extended reconstructed sea surface temperature, version 5 (ersstv5): Upgrades, validations, and intercomparisons. J. Clim. 30, 8179 - 8205, DOI: 10.1175/JCLI-D-16-0836.1 (2017). 
43. RSMC. Report on cyclonic disturbances over the north Indian Ocean during $2017 . \quad$ Tech. Rep. ESSO/IMD/CWD Report-01(2018)/15, India Meteorological Department, New Delhi (2018). Available at http://www.rsmcnewdelhi.imd.gov.in/images/pdf/publications/annual-rsmc-report/RSMC-2017.pdf.

\section{Acknowledgements}

The authors thank Dr. V. Praveen and Dr. Hamza Bangalath for helpful conversations. The Center for Prototype Climate Modeling is fully supported by the Abu Dhabi Government through New York University Abu Dhabi Research Institute Grant. The NYUAD High Performance Computing resources were used for the analysis. This work was supported by the Monsoon Mission project of the Ministry of Earth Sciences, Government of India (Grant No. MM/SERP/NYU/2014/SSC-01/002) to RSA, and the Office of Naval Research (ONR, N00014-1601-3091) to PR.

\section{Author contributions statement}

S.R and R.S.A conceived the idea; S.R and C. T. performed the research and R.S.A and P.R wrote the paper. S.T, S-P.X, K.M.K and M.R performed some aspects of the research and co-wrote the paper. M. M provided advise on data and co-wrote the paper. 


\section{Supplementary Files}

This is a list of supplementary files associated with this preprint. Click to download.

- SupportingInformationforFewerNearEquatorialCyclonesinthenorthIndianOcean.pdf 